\title{
ASSESSMENT OF RENAL GRAFT FUNCTION DEPENDING ON PRETRANSPLANT MORPHOLOGY
}

\author{
Lucie Lubuska* ${ }^{\mathrm{a} *}$ Petr Bachleda ${ }^{\mathrm{b}}$, Tomas Tichy ${ }^{\mathrm{c}}$, Marek Lubusky ${ }^{\mathrm{d}}$, Petr Utikal ${ }^{\mathrm{b}}$, \\ Monika Hrabalova ${ }^{e}$, Josef Chudacek ${ }^{\mathrm{e}}$, Vladimir Janout ${ }^{\mathrm{f}}$
}

\author{
a Department of Intensive Care in Surgery Branches, Palacký University, University Hospital, Olomouc, Czech Republic \\ ${ }^{b} 2^{\text {nd }}$ Department of Surgery, Palacký University, University Hospital, Olomouc \\ ${ }^{c}$ Department of Pathology, Palacký University, Olomouc \\ ${ }^{d}$ Department of Obstetrics and Gynecology, Palacký University, University Hospital, Olomouc \\ e $1^{\text {st }}$ Department of Surgery, Palacký University, University Hospital, Olomouc \\ ${ }^{f}$ Department of Preventive Medicine, Palacký University, Olomouc \\ e-mail:lubuskal@fnol.cz
}

Received: February 24, 2006; Accepted: April 2, 2006

Key words: Kidney transplantation/Pre-transplant wedge renal biopsy/Glomerulosclerosis/Arteriolar hyalinisation/Arterial intimal fibroplasias/Interstitial fibrosis/Tubular changes/Transplant outcome

Background: Histopathological assessment of kidney prior to transplantation is a part of the comprehensive information gathered on the transplanted organ. In our study we monitor the influence of individual morphological findings (glomeruli, arteries, arterioles, interstitium, tubules) and degree of histopathological changes in the kidney function after transplantation.

Methods: From 1994 to 1997, 117 cadaveric kidneys were histopathologically examined and subsequently transplanted. Biopsy in a form of wedge excision was obtained during the organ procurement after in situ kidney perfusion and its removal from donor's body. Evaluated were glomerulosclerosis, intimal fibrosis of arteries, arteriolar hyalinization, interstitial fibrosis and tubular changes (vacuolar dystrophy of tubular epithelium, desquamation of tubular epithelium, brush border of proximal tubules, tubular dilatation, haemoglobin cylinders in distal tubules). Kidney recipients were monitored both for immediate function of transplanted organ and long-term kidney function for a period of five years following.

Results: In our group of patients, no unambiguously negative influence of histopathological change in individual morphologies was found either in the immediate or in the long-term function of the transplanted kidney.

Conclusion: It is possible to transplant kidneys and attain satisfactory results even with these types of histopathological changes: glomerulosclerosis greater or equal to $20 \%$, mild degree of arterial lesion, moderate arteriolar lesions, moderate lesions of interstitial fibrosis and tubular lesions. The degree of arterial lesions, arteriolar lesions and the degree of interstitial fibrosis closely correlate to the donor's age, hypertension and nontraumatic cerebrovascular accident as the cause of death. Same outcomes were also confirmed with glomerulosclerosis, with the exception of the influence of the donor's age.

\section{INTRODUCTION}

Over the past decades, transplant medicine as a multi-disciplinary branch has undergone many significant changes. Satisfactory results are being achieved nowadays with both short- and long-term success. $90 \%$ of renal gafts ${ }^{1}$ survive one year after kidney transplantation. Mortality of patients with kidneys form ideal donors has dropped from 56 cases per 1000 patients in 1998 to 48 deaths per 1000 patients in $2002^{2}$. However, the scarcity of kidneys suitable for transplantation persists. This situation is particularly apparent abroad due to the higher incidence of patients with chronic renal failure waiting for transplantation and lack of donors. In quest to increase the number of available organs, so called expanded criteria for cadaveric donors are being put into practice enabling transplantation of kidneys that would have never been considered before. Detailed information on donated organ can be obtained from pre-transplant biopsy. This can reveal even those kidney disorders that remained latent during the donor's life. The aim is to assess the kidney condition in relation to the donor's age, associated diseases and to evaluate damage related to kidney procurement. Both acute and chronic changes are being monitored. The performance of pre-transplant biopsy also enabled us to recognize changes that occur in the graft only after transplantation, e.g. chronic nephropathy, cyclosporine nephrotoxicity, etc. ${ }^{3,4}$. The outcome of transplantation can be influenced by other risk factors as well. There are always numerous immune and non-immune effects that may impact on the graft even after successfully performed transplantation. These factors can subsequently lead to graft damage and 
impair its function and survival ${ }^{4-8}$. Among risk factors on the donor's side belongs kidney from a non-heartbeating donor, inotropic support of the donor, use of cold storage preservation instead of pulsatil perfusion, extended cold ischemia time, age over 55, diabetes mellitus or hypertensive disease in anamnesis. Unfavourable effects on the graft function may be caused by hypovolaemia on recipient's side, by perioperative administration of albumin, haemodialysis with ultrafiltration performed $24 \mathrm{~h}$ prior transplantation, the number of previous transplantations, patient's weight, thrombophilia condition, OKT3 therapy (orthoclon), presence of antiphospholipid antibodies, performed cytotoxic antibodies, acute tubular necrosis (ATN), cyclosporine nephrotoxicity, urinal fistula or obstruction $^{8}$.

Pre-transplant biopsy enables histopathological assessment of some morphological changes that have significant prognostic effects on the function and survival of the graft ${ }^{9}$. An array of factors has been examined for prognostic purposes, particularly conditions affecting glomeruli (glomerulosclerosis), interstitium (fibrosis), arteries, arterioles (intimal fibrosis and hyalinization) and tubules (vacuolar dystrophy, brush border, desquamation of epithelium, tubular dilatation, presence of haemoglobin cylinders).

In our study we evaluated the above specified morphological parameters and degree of their histopathological changes from the viewpoint of their influence on the graft function in post-transplant period.

\section{Objectives of the work - Prognostic factor of the graft function}

- Examination of histopathological changes of glomeruli, arteries, arterioles, interstitium and tubules of transplanted cadaveric kidneys and subsequent evaluation of impact of these morphological changes on immediate and long-term function of the graft in posttransplant period.

- Determination of relation between degree of morphological histopathological changes of the graft and the donor's age, presence of hypertension on donor's side and nontraumatic cerebrovascular accident as the cause of donor's death.

\section{MATERIALS AND METHODS}

During 1994-1997 a total of 117 cadaveric grafts were examined and transplanted. The age of donors ranged from 6 to 77 years (average - 37.6; median - 39.0). All transplantations were performed at the Transplant Centre in Olomouc Teaching Hospital and the grafts were histopathologically examined at the Institute of Pathological Anatomy of Palacký University Faculty of Medicine in Olomouc. The graft function was monitored for a period of five years after transplantation. Immediate graft function was evaluated in the first week after transplantation as a primary function, delayed function and afunction. Long-term function was evaluated after 1, 2, 3, 4 and 5
Table 1. Classification of histopathological evaluation of biopsy samples.

Percentage of sclerotic glomeruli (glomerulosclerosis, GS) was calculated from the whole number of present and sclerotic glomeruli in sample

- $0-9 \%$

- $10-19 \%$

- $\geq 20 \%$

Arterial and arteriolar damage was evaluated based on the presence of intimal fibrosis and hyalinization in the wall

0 - insudates absent

1 - mild changes (interfering wall thickening $\leq 25 \%$ transillumination)

2 - moderate changes (interfering wall thickening $\leq 50 \%$ transillumination)

3 - severe changes (interfering wall thickening > $50 \%$ transillumination)

Interstitial fibrosis (IF)

0 - absent

1 - mild changes (interfering nidus $\leq 25 \%$ of the sample)

2 - moderate changes (interfering nidus $\leq 50 \%$ of the sample)

3 - severe changes (interfering nidus $>50 \%$ of the sample)

\section{Vacuolar dystrophy of tubules (VD)}

0 - absent

1 - mild changes (affection $\leq 25 \%$ of the sample)

2 - moderate changes (affection $\leq 50 \%$ of the sample)

3 - severe changes (affection $>50 \%$ of the sample)

Epithelial desquamation of tubules (ED)

0 - absent

1 - present

Brush border of proximal tubules (BB)

0 - preserved undamaged

1 - damaged

Tubular dilatation (TD)

0 - absent

1 - present

Haemoglobin cylinders in distal tubules (HC)

0 - absent

1 - present

years, and over all those periods the number of functional and afunctional grafts was monitored. The serum creatinine level determined by Jaffe reaction without proteinace assessed the quality aspect of the graft function within all monitored periods.

Biopsy sample in a form of wedge excision was obtained at the time of organ procurement from the pole of cadaveric graft after in situ kidney perfusion and its 
Table 2. Percentual representation of individual types of morphological changes according to previous classification (see Table 1). GS - glomerulosclerosis; IF - interstitial fibrosis; VD - vacuolar dystrophy; ED - epithelial desquamation; BB - brush border; TD - tubular dilatation; HC - haemoglobin cylinders.

\begin{tabular}{|c|c|}
\cline { 2 - 2 } \multicolumn{1}{c|}{} & $\%$ \\
\hline GS $0-9 \%$ & 76 \\
\hline GS $10-19 \%$ & 18 \\
\hline GS $\geq 20 \%$ & 6 \\
\hline
\end{tabular}

\begin{tabular}{|c|c|c|c|c|}
\cline { 2 - 5 } \multicolumn{1}{c|}{} & \multicolumn{4}{c|}{ degree of changes } \\
\hline Arteries & 73.5 & 26.5 & & \\
\hline Arterioles & 48 & 43 & 9 & \\
\hline IF & 47 & 35 & 18 & \\
\hline VD & 15 & 15 & 19 & 51 \\
\hline ED & 92 & 8 & & \\
\hline BB & 45 & 55 & & \\
\hline TD & 24 & 76 & & \\
\hline HC & 60 & 40 & & \\
\hline
\end{tabular}

Table 3a. Graft function 1 week after transplantation.

\begin{tabular}{|lc|c|c|c|c|}
\cline { 3 - 6 } \multicolumn{1}{c|}{} & 117 & $\begin{array}{c}\text { afunction } \\
\mathrm{n}=8\end{array}$ & $\begin{array}{c}\text { function } \\
\mathrm{n}=109\end{array}$ & $\mathrm{P}$ & Odds ratio \\
\hline arterial damage & $\mathrm{n}=31$ & 3 & 28 & 0.46 & $1.71(0.30-9.13)$ \\
\hline arteriolar damage & $\mathrm{n}=61$ & 5 & 56 & 0.54 & $1.58(0.31-8.84)$ \\
\hline interstitial fibrosis & $\mathrm{n}=62$ & 6 & 56 & 0.19 & $2.84(0.49-21.38)$ \\
\hline vacuolar dystrophy & $\mathrm{n}=82$ & 4 & 78 & 0.19 & $0.40(0.08-2.05)$ \\
\hline epith. desquamation & $\mathrm{n}=9$ & 1 & 8 & 0.59 & not estimated \\
\hline brush border & $\mathrm{n}=64$ & 4 & 60 & 0.78 & $0.82(0.16-4.15)$ \\
\hline tubular dilatation & $\mathrm{n}=89$ & 8 & 81 & 0.32 & $2.77(0.32-61.55)$ \\
\hline haemogl. cylinders & $\mathrm{n}=46$ & 3 & 43 & 0.91 & $0.92(0.16-4.75)$ \\
\hline $\mathrm{GS} \geq 20 \%$ & $\mathrm{n}=7$ & 1 & 6 & 0.42 & $2.45(0.0-26.96)$ \\
\hline
\end{tabular}

Table 3b. Graft function 1 week after transplantation.

\begin{tabular}{|lc|c|c|c|c|}
\cline { 3 - 6 } \multicolumn{1}{c|}{} & 109 & $\begin{array}{c}\text { delayed function } \\
\mathrm{n}=42\end{array}$ & $\begin{array}{c}\text { primary function } \\
\mathrm{n}=67\end{array}$ & $\mathrm{P}$ & Odds ratio \\
\hline arterial damage & $\mathrm{n}=28$ & 13 & 15 & 0.31 & $1.55(0.60-4.05)$ \\
\hline arteriolar damage & $\mathrm{n}=56$ & 24 & 32 & 0.34 & $1.46(0.62-3.42)$ \\
\hline interstitial fibrosis & $\mathrm{n}=56$ & 26 & 30 & 0.08 & $2.00(0.85-4.76)$ \\
\hline vacuolar dystrophy & $\mathrm{n}=78$ & 32 & 46 & 0.39 & $1.46(0.56-3.86)$ \\
\hline epith. desquamation & $\mathrm{n}=8$ & 6 & 2 & 0.02 & $5.42(0.91-41.18)$ \\
\hline brush border & $\mathrm{n}=60$ & 30 & 30 & 0.006 & $3.08(1.26-7.67)$ \\
\hline tubular dilatation & $\mathrm{n}=81$ & 28 & 53 & 0.14 & $0.53(0.20-1.38)$ \\
\hline haemogl. cylinders & $\mathrm{n}=43$ & 26 & 17 & 0.000 & $4.78(1.92-12.02)$ \\
\hline GS $220 \%$ & $\mathrm{n}=6$ & 1 & 5 & 0.25 & $0.30(0.01-2.84)$ \\
\hline
\end{tabular}


removal from the donor's body. Each sample was fixed by $10 \%$ formalin, and then processed and embedded in paraffin. Histological slices of 3-4 micrometers were stained with haematoxylin-eosin. The brush border of proximal tubules was evaluated in PAS (Periodic Acid Schiff) staining. Trichrome staining according to van Gieson was applied to evaluate fibrosis, and basal membranes of glomeruli and tubules were visualized by staining according to Jones. All samples were evaluated by means of light microscopy in harmony with the classification stated in Tab. 1.

Statistical analysis was performed by software Statistica Version 6 and Epi Info Version 6. All values with $p<0.01$ were considered statistically significant.

\section{RESULTS}

Proportional representation of individual types of morphological changes according to classification in Table No. 1 is stated in percentage in Table No. 2. The connection between histopathological findings and graft function in a time-dependent manner from the date of transplantation are shown in detail in Tables No. 3-9.

The statistic result showed significantly higher number of grafts with delayed function at the end of week 1 after transplantation with histopathological finding of epithe- lial desquamation ( $\mathrm{P}$ 0.02; OR 5.42; 95 \% CI 0.91-41.18), presence of haemoglobin cylinders $(\mathrm{P}<0.001$; OR 4.78; $95 \%$ CI 1.92-12.02) and loss of brush border (P 0.006; OR 3.08, 95 \% CI 1.26-7.67). Differences between the number of functional and afunctional grafts with these morphological changes had no statistical significance. No statistically significant difference in the number of grafts with primary function, delayed function or afunction were found at the end of week 1 with histopathological lesions of glomeruli, interstitium, arteries, arterioles, presence of tubular dilatation and vacuolar dystrophy.

When evaluating the number of afunctional grafts in 1, 2, 3, 4 and 5 years after transplantation, we were able to prove a statistically significant difference only with histopathological finding of a brush border loss 1 year after transplantation (P 0.02; OR 0.12; 95 \% CI 0.01-1.05) and presence of vacuolar dystrophy after 2 years (P 0.03; OR 0.25 ; $95 \%$ CI 0.05-1.12) and after 3 years (P 0.03; OR 0.26; $95 \%$ CI 0.06-1.17). Both morphological changes did however prove a protective effect on the graft function. The serum creatinine levels rose with the degree of lesion and lapse of time after the transplantation. At the end of year 5, the grafts with higher degree of histopathological damage demonstrated the highest levels of serum creatinine. The only exemption of levels was found with mild degree of vacuolar dystrophy in the $1^{\text {st }}, 3^{\text {rd }}$, and $5^{\text {th }}$ year and with epithelial desquamation in the $1^{\text {st }}$ year. The study

Table 4. Graft function 1 year after transplantation.

\begin{tabular}{|ll|c|c|c|c|}
\cline { 3 - 6 } \multicolumn{1}{c}{} & 106 & $\begin{array}{c}\text { afunction } \\
\mathrm{n}=7\end{array}$ & $\begin{array}{c}\text { function } \\
\mathrm{n}=99\end{array}$ & $\mathrm{P}$ & Odds ratio \\
\hline arterial damage & $\mathrm{n}=28$ & 3 & 25 & 0.30 & $2.22(0.36-12.93)$ \\
\hline arteriolar damage & $\mathrm{n}=55$ & 4 & 51 & 0.77 & $1.25(0.22-7.53)$ \\
\hline interstitial fibrosis & $\mathrm{n}=56$ & 4 & 52 & 0.81 & $1.21(0.21-7.23)$ \\
\hline vacuolar dystrophy & $\mathrm{n}=74$ & 3 & 71 & 0.10 & $0.30(0.05-1.70)$ \\
\hline epith. desquamation & $\mathrm{n}=7$ & 0 & 7 & 0.57 & not estimated \\
\hline brush border & $\mathrm{n}=59$ & 1 & 58 & 0.02 & $0.12(0.01-1,05)$ \\
\hline tubular dilatation & $\mathrm{n}=82$ & 4 & 78 & 0.18 & $0.36(0.06-2.22)$ \\
\hline haemogl. cylinders & $\mathrm{n}=42$ & 1 & 41 & 0.15 & $0.24(0.01-2.11)$ \\
\hline GS $\geq 20 \%$ & $\mathrm{n}=6$ & 1 & 5 & 0.30 & $3.13(0.0-37.88)$ \\
\hline
\end{tabular}

Table 5. Graft function 2 years after transplantation.

\begin{tabular}{|lc|c|c|c|c|}
\cline { 3 - 6 } \multicolumn{1}{c|}{} & 105 & $\begin{array}{c}\text { afunction } \\
\mathrm{n}=10\end{array}$ & $\begin{array}{c}\text { function } \\
\mathrm{n}=95\end{array}$ & $\mathrm{P}$ & Odds ratio \\
\hline arterial damage & $\mathrm{n}=28$ & 3 & 25 & 0.80 & $1.20(0.22-5.76)$ \\
\hline arteriolar damage & $\mathrm{n}=55$ & 6 & 49 & 0.61 & $1.41(0.32-6.43)$ \\
\hline interstitial fibrosis & $\mathrm{n}=56$ & 6 & 50 & 0.65 & $1.35(0.31-6.16)$ \\
\hline vacuolar dystrophy & $\mathrm{n}=73$ & 4 & 69 & 0.03 & $0.25(0.05-1.12)$ \\
\hline epith. desquamation & $\mathrm{n}=7$ & 0 & 7 & 0.83 & not estimated \\
\hline brush border & $\mathrm{n}=58$ & 3 & 55 & 0.09 & $0.31(0.06-1.46)$ \\
\hline tubular dilatation & $\mathrm{n}=81$ & 6 & 75 & 0.17 & $0.40(0.09-1.89)$ \\
\hline haemogl. cylinders & $\mathrm{n}=42$ & 2 & 40 & 0.17 & $0.34(0.05-1.90)$ \\
\hline GS $20 \%$ & $\mathrm{n}=6$ & 1 & 5 & 0.53 & not estimated \\
\hline
\end{tabular}


Table 6. Graft function 3 years after transplantation.

\begin{tabular}{|lc|c|c|c|c|}
\cline { 3 - 6 } \multicolumn{1}{c|}{} & 99 & $\begin{array}{c}\text { afunction } \\
\mathrm{n}=10\end{array}$ & $\begin{array}{c}\text { function } \\
\mathrm{n}=89\end{array}$ & $\mathrm{P}$ & Odds ratio \\
\hline arterial damage & $\mathrm{n}=27$ & 3 & 24 & 0.83 & $1.16(0.22-5.60)$ \\
\hline arteriolar damage & $\mathrm{n}=52$ & 6 & 46 & 0.61 & $1.40(0.32-6.43)$ \\
\hline interstitial fibrosis & $\mathrm{n}=54$ & 6 & 48 & 0.13 & $0.44(0.13-1.47)$ \\
\hline vacuolar dystrophy & $\mathrm{n}=68$ & 4 & 64 & 0.03 & $0.26(0.06-1.17)$ \\
\hline epith. desquamation & $\mathrm{n}=7$ & 0 & 7 & 0.88 & not estimated \\
\hline brush border & $\mathrm{n}=54$ & 3 & 51 & 0.10 & $0.32(0.06-1.50)$ \\
\hline tubular dilatation & $\mathrm{n}=75$ & 6 & 69 & 0.22 & $0.43(0.09-2.06)$ \\
\hline haemogl. cylinders & $\mathrm{n}=41$ & 2 & 39 & 0.14 & $0.32(0.04-1.78)$ \\
\hline GS $\geq 20 \%$ & $\mathrm{n}=5$ & 1 & 4 & 0.45 & $2.36(0.0-27.76)$ \\
\hline
\end{tabular}

Table 7. Graft function 4 years after transplantation.

\begin{tabular}{|ll|c|c|c|c|}
\cline { 3 - 6 } \multicolumn{1}{c|}{} & 94 & $\begin{array}{c}\text { afunction } \\
\mathrm{n}=14\end{array}$ & $\begin{array}{c}\text { function } \\
\mathrm{n}=80\end{array}$ & $\mathrm{P}$ & Odds ratio \\
\hline arterial damage & $\mathrm{n}=26$ & 4 & 22 & 0.93 & $1.05(0.35-4.22)$ \\
\hline arteriolar damage & $\mathrm{n}=50$ & 9 & 41 & 0.36 & $1.71(0.47-6.52)$ \\
\hline interstitial fibrosis & $\mathrm{n}=51$ & 8 & 43 & 0.81 & $1.15(0.32-4.16)$ \\
\hline vacuolar dystrophy & $\mathrm{n}=65$ & 8 & 57 & 0.29 & $0.54(0.15-1.99)$ \\
\hline epith. desquamation & $\mathrm{n}=7$ & 0 & 7 & 0.78 & not estimated \\
\hline brush border & $\mathrm{n}=53$ & 5 & 48 & 0.09 & $0.37(0.10-1.36)$ \\
\hline tubular dilatation & $\mathrm{n}=72$ & 9 & 63 & 0.23 & $0.49(0.12-1.94)$ \\
\hline haemogl. cylinders & $\mathrm{n}=40$ & 3 & 37 & 0.08 & $0.32(0.06-1.36)$ \\
\hline GS $\geq 20 \%$ & $\mathrm{n}=5$ & 1 & 4 & 0.74 & not estimated \\
\hline
\end{tabular}

Table 8. Graft function 5 years after transplantation.

\begin{tabular}{|c|c|c|c|c|c|}
\hline & 91 & $\begin{array}{c}\text { afunction } \\
n=16\end{array}$ & $\begin{array}{c}\text { function } \\
n=75\end{array}$ & $\mathrm{P}$ & Odds ratio \\
\hline arterial damage & $\mathrm{n}=26$ & 4 & 22 & 0.72 & $0.80(0.19-3.11)$ \\
\hline arteriolar damage & $\mathrm{n}=49$ & 10 & 39 & 0.44 & $1.54(0.45-5.37)$ \\
\hline interstitial fibrosis & $\mathrm{n}=50$ & 9 & 41 & 0.90 & $1.07(0.32-3.60)$ \\
\hline vacuolar dystrophy & $\mathrm{n}=62$ & 10 & 52 & 0.59 & $0.74(0.21-2.62)$ \\
\hline epith. desquamation & $\mathrm{n}=7$ & 0 & 7 & 0.64 & $0.61(0.03-5.62)$ \\
\hline brush border & $\mathrm{n}=51$ & 7 & 44 & 0.27 & $0.55(0.16-1.83)$ \\
\hline tubular dilatation & $\mathrm{n}=69$ & 11 & 58 & 0.46 & $0.64(0.17-2.49)$ \\
\hline haemogl. cylinders & $\mathrm{n}=39$ & 4 & 35 & 0.11 & $0.38(0.09-1.44)$ \\
\hline $\mathrm{GS} \geq 20 \%$ & $\mathrm{n}=5$ & 1 & 4 & 0.88 & not estimated \\
\hline
\end{tabular}

Table 9. Odds ratio - afunction / function.

\begin{tabular}{|l|c|c|c|c|c|c|}
\cline { 2 - 6 } \multicolumn{1}{c|}{} & week 1 & year 1 & year 2 & year 3 & year 4 & year 5 \\
\hline arterial damage & 1.71 & 2.22 & 1.20 & 1.16 & 1.05 & 0.80 \\
\hline arteriolar damage & 1.58 & 1.25 & 1.41 & 1.40 & 1.71 & 1.54 \\
\hline interstitial fibrosis & 2.84 & 1.21 & 1.35 & 0.44 & 1.15 & 1.07 \\
\hline vacuolar dystrophy & 0.40 & 0.30 & 0.25 & 0.26 & 0.54 & 0.74 \\
\hline epith. desquamation & & & & & & 0.61 \\
\hline brush border & 0.82 & 0.12 & 0.31 & 0.32 & 0.37 & 0.55 \\
\hline tubular dilatation & 2.77 & 0.36 & 0.40 & 0.43 & 0.49 & 0.64 \\
\hline haemogl. cylinders & 0.92 & 0.24 & 0.34 & 0.32 & 0.32 & 0.38 \\
\hline GS $\geq 20 \%$ & 2.45 & 3.13 & & 2.36 & & \\
\hline
\end{tabular}


showed clear correlation between degree of histopathological changes in arteries, arterioles, interstitial fibrosis and the donor's age, hypertensive disease and nontraumatic cerebrovascular accident as cause of death. Same outcomes were confirmed with glomerulosclerosis, except for the influence of donor's age.

\section{DISCUSSION}

Performance of pre-transplant biopsy followed by histopathological evaluation of morphological finding in kidney provides more comprehensive information on transplanted organ. The professional literature published many studies focussing on the influence of detected degree of lesion in individual morphological parameters on immediate and long-term kidney function after transplantation. The majority of these studies analysed the impact of lesion in glomeruli, arteries or interstitial lesions, some also reflect tubular lesions. In our work, we observed all four prime morphological units.

The percentage of defective glomeruli in the case of glomerulosclerosis (GS) in our patient group had no influence on immediate or long-term function of transplanted kidney. We noticed no negative impact on graft function in patients with glomerulosclerosis $\geq 20 \%$. Other works describe the same results ${ }^{5,10}$. Some studies on the contrary quote impaired graft function with this degree of glomerulosclerosis ${ }^{11,12}$. Gaber et al. ${ }^{11}$ states that delayed graft function occurred in $87 \%$ with glomeruli affection $\geq 20 \%$. Escofet et al. ${ }^{12}$ demonstrates the five-year survival in $35 \%$. In our group of patients, we recorded delayed function only in $17 \%$ with the same degree of glomeruli affection and five-year graft survival in $57 \%$. In harmony with the literature we confirmed the correlation between glomerulosclerosis degree and the hypertension of the donor and nontraumatic cerebrovascular accident as cause of death ${ }^{10,11}$. However we did not confirm any relation between donor's age and degree of glomeruli impairment also described in the literature ${ }^{5,10,11,13-15}$.

The degree of arterial and arteriolar lesions in our group of patients had no significant influence on immediate or long-term graft function. The significance of arterial lesions is disputed and questioned by other studies as well ${ }^{10,14,16,17}$. Nevertheless, other authors showed the influence of arterial changes on the post-transplant kidney function $^{4,16,18-24}$. In our group only mild arterial lesions were noticed, no moderate or severe lesions. As for arterioles, we evaluated mild and moderate changes, no severe changes were recorded. In harmony with the literature we confirmed the correlation between the degree of arterial and arteriolar lesions and donor's age, hypertension and nontraumatic cerebrovascular accident as cause of death $^{4,14,21-23,25-27}$.

The degree of graft lesion caused by interstitial fibrosis did not influence the immediate or long-term function of the graft. There was no case demonstrating severe changes. Nonetheless, there are cases in the literature which report the influence of this parameter on graft function $^{14,16,28,29}$. Other authors, in contrast, validate our results $^{16,17,24,30}$. In the case of interstitial fibrosis we found a link between degree of lesions and donor's age, hypertension and nontraumatic cerebrovascular accident as the cause of death. The literature describes only the correlation between the donor's age and the degree of interstitial fibrosis $^{14,21,27,31,32}$.

In the case of tubules we evaluated the degree of vacuolar dystrophy, presence of epithelial desquamation, loss of brush border, presence of tubular dilatation and presence of haemoglobin cylinders in distal tubules. A negative impact on immediate function of the graft was recorded for epithelial desquamation, presence of haemoglobin cylinders and loss of brush border. The cases described in the literature deal only with the epithelial desquamation and vacuolization. A negative impact of these morphological changes on delayed graft function has been proved ${ }^{3,5,16,17,30,33}$. Influence on the long-term function was observed only in the case of vacuolar dystrophy and loss of brush border, but both morphological changes, on the contrary, showed protective effects on graft function. We found nothing in the literature describing similar findings. Pokorná et al. ${ }^{5}$ analyses the negative impact of vacuolization and desquamation presence on immediate and late level of graft function.

\section{CONCLUSION}

It is possible to transplant kidneys and attain both short- and long-term satisfactory results even with a mild degree of arterial lesion, moderate degree of arteriolar lesion, moderate degree of interstitial fibrosis, glumerulosclersis greater or equal to $20 \%$ and tubular cells lesions. The donor's age, hypertension and nontraumatic cerebrovascular accident as the cause of death demonstrate a direct correlation with the degree of arterial and arteriolar lesions and with degree of interstitial fibrosis. The same outcomes have also been confirmed with glomerulosclerosis, except for the influence of donor's age. It is advisable to perform biopsy of the kidney on donors over 40 years of age with hypertension and nontraumatic cerobrovascular accident as the cause of death. However, the pretransplant biopsy is just one of many factors contributing to the outcome of transplantation.

\section{REFERENCES}

1. Danovitch GM. Handbook of kidney transplantation. Philadelphia: Lippincott Williams and Wilkins, 2005.

2. United Network for organ Sharing (UNOS) data base. http://www. optn.org/AR.2004/chapter.AR.cd.htm

3. Randhawa P. (2001) Role of donor kidney biopsies in renal transplantation. Transplantation 71, 1361-5.

4. Oda A, Morozumi K, Uchida K. (1999) Histological factors of 1-h biopsy influencing the delayed renal function and outcome in cadaveric renal allografts. Clin Transplant 13, 6-12.

5. Pokorná E, Vítko Š, Chadimová M, Schuck O, Ekberg H. (2000) Proportion of glomerulosclerosis in procurement wedge renal biopsy cannot alone discriminate for acceptance of marginal donors. Transplantation 69, 36-43. 
6. Lechevallier E, Dussol B, Luccioni A, Thirion X, Vacher-Copomat H, Jaber K, Brunet P, Leonetti F, Lavelle O, Coulange C, Berland Y. (1998) Posttransplantation acute tubular necrosis: risk factors and implications for graft survival. Am J Kidney Dis 32, 984-91.

7. Metzger RA, Delmonico FL, Feng S, Port FK, Wynn JJ, Merion RM. (2003) Expanded criteria donors for kidney transplantation. Am J Transplant 3, 114-25.

8. Perico N, Cattaneo D, Sayegh MH, Remuzzi G. (2004) Delayed graft function in kidney transplantation. Lancet 364, 1814-27.

9. Di Paolo S, Stallone G, Schena A, Infante B, Gesualdo L, Paolo Schena F. (2002) Hypertension is an independent predictor of delayed graft function and worse renal function only in kidney with chronic pathological lesions. Transplantation 73, 623-7.

10. Lu AD, Desai D, Myers BD, Dafoe DC, Alfrey EJ. (2000) Severe glomerular sclerosis is not associated with poor outcome after kidney transplantation. Am J Surg 180, 470-4.

11. Gaber LW, Moore LW, Alloway RR, Amiri MH, Vera SR, Gaber AO. (1995) Glomerulosclerosis as a determinant of posttransplant function of older donor renal allografts. Transplantation $60,334-$ 9.

12. Escofet X, Osman H, Griffiths DF, Woydag S, Adam JW. (2003) The presence of glomerular sclerosis at time zero has a significant impact on function after cadaveric renal transplantation. Transplantation 75, 344-6.

13. Duman S, Ozbek S, Sen S, Tamsel S, Toz H, Asci G, Ozkahya M, Sezis M, Ok E, Hoscoskun C. (2004) Is „zero-hour“ biopsy of the transplanted kidney risky? Transplant Proc 36, 137-8.

14. Randhawa PS, Minervini MI, Lombardero M, Duquesnoy R, Fung J, Shapiro R, Jordan M, Vivas C, Scantlebury V, Demetris A. (2000) Biopsy of marginal donor kidneys: correlation of histologic findings with graft dysfunction. Transplantation 69, 1352-7.

15. Cosyns JP, Malaise J, Hanique G, Mourad M, Baldi A, Goebbels RM, Squifflet JP. (1998) Lesions in donor kidneys: nature, incidence, and influence on graft function. Transpl Int 11, 22-7.

16. Papadimitriou JC, Coale R, Farney A, Schweitzer E, Foster C, Campos L, Bartlett S. (2004) Biopsy of the marginal kidney donor: correlation of histology with outcome. Transplant Proc 36, 742-4.

17. Pokorná E, Vítko S̆, Chadimová M, Schuck O. (2001) Morphologic changes in renal procurement biopsy and onset of graft function. Transplant Proc 33, 1999-2000.

18. Bosmans JL, Woestenburg AT, Helbert MJ, Ysebaert DK, Van Marck E, De Broe ME, Verpooten GA. (2000) Impact of donor-related vascular alterations in implantation biopsies on morphologic and functional outcome of cadaveric renal allografts. Transplant Proc 32, 379-80.

19. Bosmans JL, Woestenburg A, Ysebaert DK, Chapelle T, Helbert MJ, Corthouts R, Jurgens A, Van Daele A, Van Marck EA, De
Broe ME, Verpooten GA. (2000) Fibrous intimal thickening at implantation as a risk factor for the outcome of cadaveric renal allografts. Transplantation 69, 2388-94.

20. Szakaly P, Magyarlaki T, Kalmar NK. (2001) Clinical value of „zero-hour“ biopsy in kidney transplantation. Magy Seb 54, 18 22.

21. Pokorná E, Vítko Š, Chadimová M, Schuck O. (2000) Adverse effect of donor arteriosclerosis on graft outcome after renal transplantation. Nephrol Dial Transplant 15, 705-10.

22. Minakawa R, Tyden G, Lindholm B, Reinholt FP. (1996) Donor kidney vasculopathy: impact on outcome in kidney transplantation. Transpl Immunol 4, 309-12.

23. Karpinski J, Lajoie G, Cattran D, Fenton S, Zaltzman J, Cardella C, Cole E. (1999) Outcome of kidney transplantation from high-risk donors is determined by both structure and function. Transplantation 67, 1162-7.

24. Wang HJ, Kjellstrand CM, Cockfield SM, Solez K. (1998) On the influence of sample size on the prognostic accuracy and reproducibility of renal transplant biopsy. Nephrol Dial Transplant 13, $165-72$.

25. Sugiyama S, Tsuyuki M, Okazaki Y, Takeuchi N, Matsuura O, Ohshima S. (1994) Arteriosclerotic lesions of donor kidney and graft survival. Transplant Proc 26, 929-30.

26. Tracy RE, Strong JP, Newman WP 3rd, Malcolm GT, Oalmann MC, Guzman MA. (1996) Renovasculopathies of nephrosclerosis in relation to atherosclerosis at ages 25 to 54 years. Kidney Int 49 , 564-70.

27. Viklický O, Bohmová R, Heemann UW. (2002) The kidney ageing and transplantation. Čas Lék Česk 141, 765-8.

28. Seron D, Carrera M, Grino JM. (1993) Relationship between donor renal interstitial surface and post-transplant function. Nephrol Dial Transplant 71, 539-43.

29. Isoniemi H, von Willebrand E, Krogerus L, Taskinen E, Ahonen J, Hayry P. (1992) The effect of donor age on kidney graft function and on histopathological findings. Transplant Proc 24, 328-9.

30. Kuypers DR, Chapman JR, O Connell PJ, Allen RD, Nankivell BJ. (1999) Predictors of renal transplant histology at three months. Transplantation 67, 1222-30.

31. Kaplan C, Pasternack B, Shah H, Gallo G. (1975) Age-related incidence of sclerotic glomeruli in human kidneys. Am J Pathol 80, 227-34.

32. Goldstein RS, Tarloff JB, Hook JB (1988) Age-related nephropathy in laboratory rats. FASEB J 2, 2241-51.

33. Oberhauer R, Rohermoser M, Regele H, Muhlbacher F, Mayer G. (1999) Apoptosis of tubular epithelial cells in donor kidney biopsies predicts renal allograft function. J Am Soc Nephrol 10, 2006-13. 